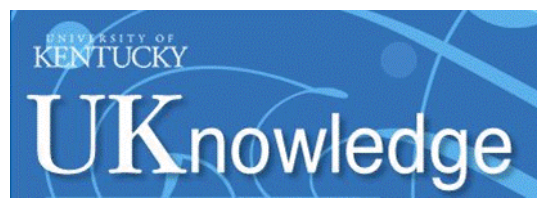

University of Kentucky

UKnowledge

\title{
Isolating Price Promotions: The Influence of Promotional Timing on Promotion Redemption
}

\author{
Daniel Sheehan \\ University of Kentucky, dan.sheehan@uky.edu \\ Koert van Ittersum \\ University of Groningen, Germany
}

Follow this and additional works at: https://uknowledge.uky.edu/marketing_facpub

Part of the Marketing Commons

Right click to open a feedback form in a new tab to let us know how this document benefits you.

\section{Repository Citation}

Sheehan, Daniel and van Ittersum, Koert, "Isolating Price Promotions: The Influence of Promotional Timing on Promotion Redemption" (2021). Marketing \& Supply Chain Faculty Publications. 3. https://uknowledge.uky.edu/marketing_facpub/3

This Article is brought to you for free and open access by the Marketing \& Supply Chain at UKnowledge. It has been accepted for inclusion in Marketing \& Supply Chain Faculty Publications by an authorized administrator of UKnowledge. For more information, please contact UKnowledge@lsv.uky.edu. 


\title{
Isolating Price Promotions: The Influence of Promotional Timing on Promotion Redemption
}

\author{
DANIEL SHEEHAN AND KOERT VAN ITTERSUM
}

\begin{abstract}
This research investigates how the timing of the promotional encounter, whether consumers encounter a promotion in isolation or at the moment of choice alongside other products, influences how consumers evaluate and redeem a promotional offer. Three studies demonstrate that isolated promotions for premium brands are more effective than traditional shelf promotions in persuading consumers to purchase the promoted product as these promotions alter how consumers evaluate and justify purchasing the promoted products. Specifically, isolated promotions lead consumers to focus relatively less on the price of the promoted product compared to its quality. This reduced focus on price assuages the negative effect of guilt associated with purchasing a more expensive, premium brand. These findings offer insights into consumer response to promotions, the most effective timing for promotions, and the best ways to optimize promotional strategies.
\end{abstract}

$\Lambda$ s recent technological advancements have changed the face of retailing, marketers have more opportunities than ever to engage and communicate with shoppers in their shopping experiences (Van Ittersum et al. 2013). Of great interest to retailers is how to use these opportunities to create meaningful communication that provides consumers value and motivates purchasing behavior. For example, retailers can now track and engage their customers with various promotional offers according to their location or the contents of their shopping basket (Hui et al. 2013). This suggests that, rather than pragmatically offering promotions alongside their products, retailers can now separate the moment shoppers encounter a promotion from the moment shoppers encounter the product.

As promotions are one of the most utilized tools in marketing, their influence on consumer decisions has been well documented (Mela, Gupta, and Lehmann 1997; Ailawadi, Neslin, and Gedenk 2001). Yet despite this abundance of research, there is conflict regarding how to best match these promotions with brands to create the most attractive promotional opportunity. Although some research has suggested that promotions are most effective when the benefits of the promotion are matched to the benefits of a product, as they work together to accentuate those benefits (Raghubir and Corfman 1999; Chandon, Wansink, and Laurent 2000), other research suggests that mismatched promotions may be better at motivating consumers to purchase a product (Kivetz and Zheng 2017). What is yet to be studied, however, is how the timing of a promotion, relative to the moment of choice (i.e., actually selecting the product), influences which benefits of the promotional opportunity are more salient to consumers when considering the purchase of a promoted brand. Stated differently, would encountering a promotional opportunity before arriving at the product on the shelf lead to higher redemption likelihoods than confronting the same promotion with the product on the shelf? We suggest that consumers evaluate a promotional offer differently, according to the manner in which consumers encounter a promotion, which leads to different aspects of the redemption decision to be more salient.

This research builds on literature regarding reason-based choice (Shafir, Simonson, and Tversky 1993) and separate versus joint evaluations (Hsee and Leclerc 1998) to propose that in-store promotions may be more effective when the benefits salient to a consumer's evaluation are congruent with the benefits of the promotional opportunity. As past research has noted, price promotions can increase the salience of price in consumer purchase decisions (Nunes and Park 2003), which adversely affects a shopper's willingness to spend money. Offering price promotions on premium brands

Daniel Sheehan (dan.sheehan@uky.edu) is assistant professor of marketing at the Gatton College of Business and Economics, University of Kentucky, Lexington, KY 40506, USA. Koert Van Ittersum (k.van.ittersum@rug.nl) is professor of marketing and consumer well-being in the Marketing Department, University of Groningen, Nettelbosje 2, 9747AE Groningen, Netherlands.

JACR, volume 6, number 1. Published online January 11, 2021. https://doi.org/10.1086/710247

(c) 2021 the Association for Consumer Research. All rights reserved. 2378-1815/2021/0601-0009\$10.00 
could be ineffective if it makes the promoted product seem too expensive (even with the promotional savings). If altering the timing of a promotion changes how consumers focus on and evaluate price (Yan and Sengupta 2011), managers may be able to mitigate this deleterious effect. We propose that shifting the moment that consumers encounter a promotion, relative to the point of purchase, reduces (increases) the relative salience of price (quality) for shoppers when they are considering purchasing the promoted product.

It is important to note that in this research, consumers see either a "shelf" promotion, where the promotional message is encountered at the moment of choice, or they see an "isolated" promotion that is encountered in a distinct moment. In fact, we examine isolated promotions that can be shown to customers on mobile devices or in-store displays. Thus, not only does this research eliminate any asymmetry in the number of times a promotional offer is seen (i.e., before and at the shelf), but this process may also offer retailers guidance regarding how to personalize promotions to consumers. This allows retailers to target different types of shoppers with unique promotions at distinct points in their shopping experience according to their in-store location or the contents of their shopping baskets (Hui et al. 2013).

This article makes two important contributions. First and foremost, this is the first research to demonstrate that the moment consumers initially encounter an in-store price promotion, whether the promotion is encountered with or without the promoted product on the shelf, influences redemption. In doing so, we find that isolated promotions can be more effective for premium brands than promotions encountered at the moment of choice. Second, we contribute to research-based choice literature (Shafir et al. 1993; Hsee and Leclerc 1998; Okada 2005) by demonstrating that isolating promotions influence how shoppers evaluate the promotion and justify purchasing the promoted product. Specifically, isolated promotions are more likely to enhance consumers' focus on the quality of the promoted product, while price becomes more salient for shelf promotions. As such, this research adds to our understanding of how shoppers perceive opportunity costs in purchasing decisions by demonstrating that a promotion's timing may lead shoppers to focus on the costs of a purchase decision (Frederick et al. 2009; Nunes and Park 2003). Stated differently, while traditional shelf promotions can lead shoppers to focus on the opportunity costs of a purchase, we find that altering a promotion's timing can lead shoppers to focus more closely on a promoted product's quality than its price, which can have a beneficial influence on consumer satisfaction and spending (Aydinli, Bertini, and Lambrecht 2014).

\section{THEORETICAL BACKGROUND}

Promotions comprise a substantial portion of marketing expenditures in many industries and are used to drive sales by encouraging brand switching among shoppers, businesses, or other channel partners (Leone and Srinivasan 1996; Mela et al. 1997; Ailawadi and Neslin 1998). Brand-specific price promotions, one of the most common types of promotions, offer consumers a variety of benefits beyond simple monetary savings to attract shoppers to purchase a promoted brand (Raghubir and Corfman 1999; Chandon et al. 2000). Yet the ultimate effectiveness of a promotional offer is determined by how it aligns with product-related factors (Chandon et al. 2000; Kivetz and Zheng 2017), as specific benefits of a promotion may be more salient if they match the characteristics of the product (Chandon et al. 2000) or complement the benefits of the product (Kivetz and Zheng 2017).

Although promotions have been shown to encourage shoppers to switch to different brands, there is also evidence that suggests they can occasionally backfire for retailers by making consumers more price sensitive (Papatla and Krishnamurthi 1996; Mela et al. 1997; Nunes and Park 2003). This implies the effectiveness of promotions on expensive, premium brands could be limited if shoppers become too sensitive toward spending money and can find an acceptable product that is less expensive. As such, this research examines how changing the manner in which promotions are encountered shapes the benefits consumers derive from a promotional offer and the promotion's ultimate effectiveness.

For any purchase decision, consumers generally make trade-offs between a product's relative quality and price (Rao and Monroe 1989), which can be shaped by the context of the purchase decision (Briesch 1997; Yan and Senguta 2011). Some of these contextual factors can lead consumers to base purchase decisions primarily on a product's quality, while others increase the influence of price in consumer decision making (Van Ittersum et al. 2007). Although research has demonstrated that promotions, in general, can increase shoppers' focus on both price and quality, we suggest that the manner in which consumers encounter a promotion is an important contextual factor that dictates which one is more salient. Specifically, we argue that altering the timing of the promotional encounter changes the relative salience of the product's price and quality, influencing the consumer's decision to purchase the promoted brand. This makes different attributes of the promotion and the promoted product more salient, which produces a different justification for purchasing the promoted product or not (Bazerman et al. 1999; Okada 2005; Van Ittersum et al. 2007). 


\section{Shelf Promotions and Joint Evaluation}

One common method that retailers use to inform consumers of price promotions is to place them alongside the promoted product on the shelf. Although any promotion may draw consumers' attention to monetary considerations as the offer directly involves costs and spending (e.g., save \$.50, 15\% off), these shelf promotions also focus consumers' attention on the costs of a promoted product due to the context in which they are evaluated. In this context, consumers not only encounter information about the price promotion but also glean information about the promoted brand and competing alternatives. This influences how consumers evaluate the promotion and consider purchasing the promoted product.

Even without competing alternatives available, shelf promotions focus consumer attention on the costs of the promoted brand. In fact, consumers generally integrate the promotional savings with the product's price (Nunes and Park 2003; Biswas et al. 2013) and evaluate a promotion's attractiveness according to the absolute value of the promotion, the brands' original net price, and the difference between the two.

This focus on price is likely to be stronger when consumers encounter shelf promotions in the midst of other competing alternatives. In this context, consumers determine which option to purchase by not only evaluating the promotional savings but also comparing the potential costs of the promoted brand to the cost of purchasing other available brands. For instance, although a price promotion may make a specific brand more attractive, its attractiveness will be greater (weaker) if the promotion makes a promoted brand less (more) expensive than the other alternatives. Given the idiosyncrasies between competing alternatives and the abstract nature of non-price-related attributes (e.g., quality), the mere process of comparing options will lead consumers to focus on price information that is easier to compare across brands (Hsee and Leclerc 1998).

This line of thinking suggests that shoppers' redemption decisions for shelf promotions are ultimately driven by saving money, rather than purchasing upgraded product (Bazerman et al. 1999). Although the discount offered through shelf promotions may entice shoppers to purchase the promoted brand, this process will be primarily contingent on the final price of the product resulting from the magnitude of the savings and/or the original price of the product. If the savings offered by the promotion are not sufficient relative to the prices of the competing alternatives, the product may still be judged as too expensive and not purchased. In this case, a promoted item may seem overly indulgent, ultimately triggering guilt and dissuading consumers from purchasing the promoted product (Prelec and Loewenstein 1998; Kivetz and Simonson 2002). Stated differently, if shoppers are especially focused on price, they may choose the less expensive option to avoid feeling guilty about overspending (Okada 2005).

In sum, although promotions offer various benefits to shoppers (Chandon et al. 2000), their effectiveness in generating additional sales of premium brands may be mitigated if the promotion draws too much attention to price (Nunes and Park 2003) and enhances the perceived costs of purchasing a more expensive brand (Frederick et al. 2009). We suggest that altering when consumers encounter the promotion may alleviate this adverse effect and increase the redemption of promoted premium brands.

\section{Isolated Promotions and Separate Evaluation}

Isolated promotions are promotions shoppers encounter independently from the point-of-purchase for the promoted product. In these situations, consumers are only presented with the promotional offer (e.g., save $\$ 1.50$ on Starbucks, $50 \%$ off DiGiorno Frozen Pizza). Thus, shoppers only consider the information about the promotional opportunity rather than information that is not explicitly presented, such as the product's net price and/or relative expense compared to other options (Kahneman and Frederick 2002). Support for this premise is found in the choice literature indicating that consumers ignore competing options for goods and experiences not explicitly presented (Loewenstein and Prelec 1993; Frederick et al. 2009). Without this information, shoppers place greater weight on the benefits of the promotional opportunity and less on the opportunity costs and benefits of the competing options (Slovic 1972; Kahneman and Frederick 2002; Frederick et al. 2009). This, in turn, encourages shoppers to consider the merits of the premium brand relatively more than its costs (Hsee and Leclerc 1998; Frederick et al. 2009), lessening consumers' focus on the utilitarian savings offered by the promotion. Furthermore, research has shown that altering temporal components of a decision can alter how consumers evaluate a product's price (Yan and Senguta 2011). These both suggest that isolated promotions should be most effective for premium brands as they are generally positioned on benefits instead of costs.

In summary, we propose that isolated promotions increase the likelihood that shoppers evaluate the promoted premium brand positively and redeem the promotion. Alternatively, shelf promotions will be less effective as shoppers will be more inclined to compare it and its price to competing 
alternatives. We suggest that evaluations and purchase decisions are driven by the salience of information at the time of the purchase decision. As such, we formally propose:

H1: Isolated promotions lead to higher purchase intentions for premium products than shelf promotions.

H2: This effect of isolated promotions is driven by how isolated (shelf) promotions:

H2a: increase the relative salience of quality (price),

H2b: improve (deteriorate) evaluations of the promoted premium brand, and

H2c: assuage (enhance) the guilt associated with purchasing premium brand.

To empirically examine the influence of isolated promotions, we conducted three studies. Study 1 offers initial evidence of the benefit of isolated promotions on the redemption of premium brands, while also providing support for our theoretical framework by demonstrating that isolated promotions increase the salience of a product's quality, which subsequently drives redemption decisions. Study 2 provides corroborating evidence and finds that isolated promotions reduce the salience of price. As a result, shoppers who receive an isolated promotion experience less guilt about purchasing a premium brand and are more inclined to redeem the promotion. Study 3 tests the effect in a realistic purchase environment as study participants select brands in an experimental physical grocery store and demonstrates the mediating impact of isolated promotions on redemption via more favorable product evaluation and lower levels of guilt.

\section{STUDY 1}

Study 1 used two online tasks to investigate how promotion type influences the evaluation of the promoted product. First, participants completed a simulated shopping trip task where they would select a grocery item (out of a set of four possible options) from 11 different product categories. Then participants completed a word recognition task to examine how the promotion influenced their thoughts about the promoted product. The study was a between-subjects experiment in which 305 online participants from Amazon's Mechanical Turk (MTurk) were randomly assigned to one of three conditions (isolated promotion vs. a shelf promotion vs. no promotion control condition). Participants averaged 29.84 years old, and $51.2 \%$ were female.

\section{Procedure and Design}

At the start of the experiment, participants were told that they would complete two tasks: a simulated grocery shopping task where they would make several grocery purchases and a word recognition task that examined how they thought about one of the presented products. In the simulated shopping trip task, participants were asked to make a series of grocery purchase decisions that approximated a shopping trip. Although they would be making 11 purchase decisions, our focus was on the 11 th decision (i.e., frozen pizza) that included the promoted brand (i.e., Freschetta Frozen Pizza).

For each product category, participants were presented with four options with each featuring a picture, brand name, and price (set according to their prices at a national grocery retailer). As the focus of the study was to examine the role of a promotion type on consumers' redemption behavior, participants were randomly assigned to one of three promotion conditions. In the isolated promotion condition, participants encountered the following promotion: "Save $\$ .50$ on Freschetta Frozen Pizza. Discount to be applied at checkout" between the fourth and fifth decisions. The participants in the isolated promotion condition did not receive any additional cues when they arrived at the purchase decision with the promoted product. Participants in the shelf promotion condition encountered the promotion at the time they chose one of four options for the pizza category. Participants in the control condition received no promotion.

Immediately after the shopping task, participants completed a word recognition task designed to examine if quality perceptions of the promoted brand were more salient according to promotion type. Participants viewed a series of words, one at a time, and pressed either the $m$ or $z$ letters on their keyboard to indicate whether the word did or did not describe Freschetta Frozen Pizza. The task contained 20 words that could either describe a food product (tasty, high quality, etc.) or were completely unrelated (flower, phone, music, etc.). A complete list of the words is available in the appendix, available online. The speed with which participants identified whether the relevant words related to the promoted product served as a proxy for the salience of the promoted brand's benefits. After participants completed the recognition task, they evaluated the promoted product and provided demographic information.

\section{Measures}

Participants' purchase intentions for frozen pizza were recorded to determine whether they redeemed the promotion. We also averaged the amount of time (measured in milliseconds, 
ms) they took to respond to the food relevant words in the word recognition task to determine whether quality considerations for the product were more salient when they encountered an isolated promotion. This variable was also logtransformed to account for a skewed distribution. At the end of the survey, participants evaluated the product on a 7-point scale ( 1 = poor; $7=$ excellent).

\section{Results}

To examine the influence of promotions on participants' purchase intentions, we conducted an ANOVA with promotion condition as the independent variable and participants' intentions to purchase the promoted product as the dependent variable. Consistent with our predictions, there was a significant effect of promotion condition $\left(M_{\text {isolated }}=53.5 \%\right.$ vs. $M_{\text {shelf }}=36.6 \%$ vs. $M_{\text {control }}=24.3 \% ; F(1,302)=9.79$, $p<.001)$. Furthermore, the results of a separate chi-square test show that purchase intentions for the promoted product were higher with isolated promotions than the shelf promotions (53.5\% vs. $36.6 \%$; $\chi^{2}=5.38, p=.023$ ). These results support hypothesis 1 (see fig. 1).

The word recognition task results also support our theoretical framework. Isolated promotions led participants to think more extensively about the benefits of the promoted product. A one-way ANOVA with promotion condition as an independent variable and the logged average response time on the relevant words as the dependent variable revealed the amount of time taken to respond to the relevant words varied by promotion condition $(F(2,302)=9.30$, $p<.001$; fig. 2). Follow-up analyses indicate that participants in the isolated promotion condition responded significantly faster than those in the shelf promotion $\left(M_{\text {isolated }}=\right.$

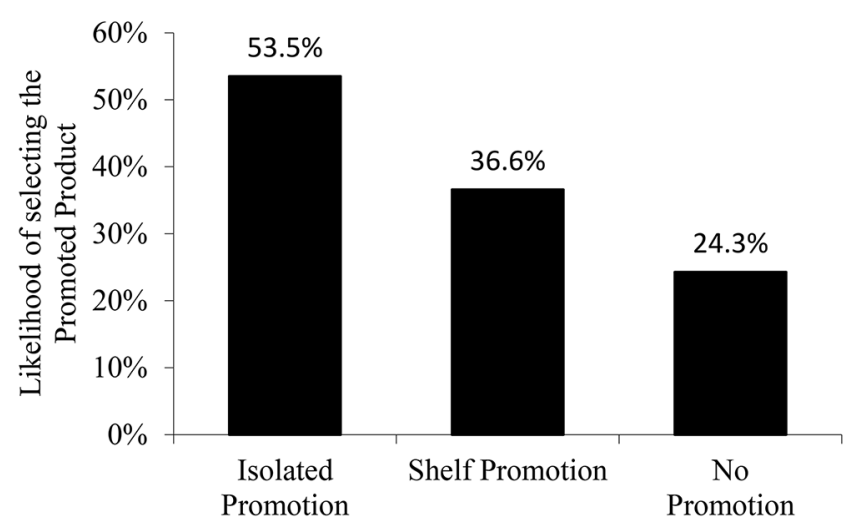

Figure 1. Purchase intentions toward the promoted product in study 1. Likelihood of selecting the promoted product is measured by participants' purchase selections. Higher values indicate that a higher percentage of participants selected that option.

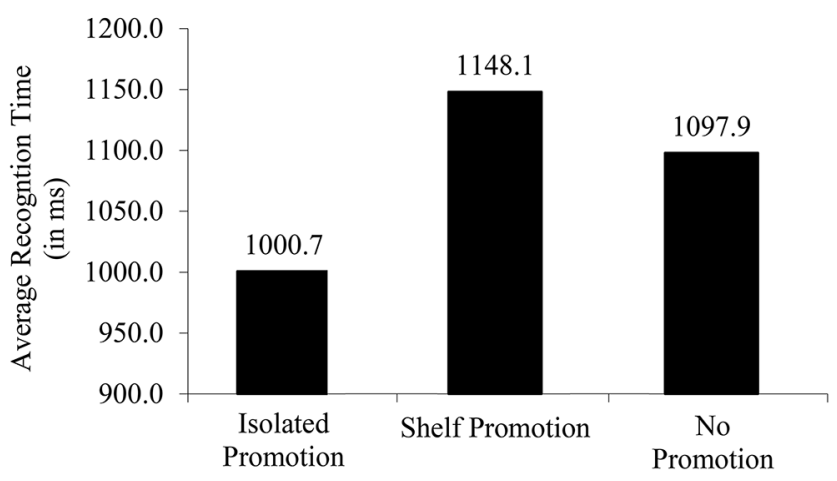

Figure 2. Average response time (before log-transformation) to words relating to product quality. Average recognition time is the average time it took participants to indicate whether a provided (food-related) word described the promoted product (or not). Lower values indicate that the product was more accessible to participants, which allowed participants to evaluate the provided word faster.

9.16 vs. $\left.M_{\text {shelf }}=9.32 ; p<.01\right)$ and control conditions $\left(M_{\text {isolated }}=9.16\right.$ vs. $\left.M_{\text {control }}=9.27 \mathrm{~ms} ; p<.01\right)$. The shelf promotion and control conditions were not significantly different. Thus, the results support hypothesis 2a.

Product evaluations provided similar results. An ANOVA with promotion condition as an independent variable revealed that evaluations of the promoted product depended upon the promotion condition $(F(2,302)=6.20, p=0.003)$. Similar to response times, follow-up analyses revealed that participants who encountered an isolated promotion gave more favorable evaluations than those in the shelf promotion $\left(M_{\text {isolated }}=\right.$ 4.51 vs. $M_{\text {shelf }}=4.05 ; p=.001$ ) and control conditions $\left(M_{\text {isolated }}=4.51\right.$ vs. $\left.M_{\text {control }}=4.18 ; p=.018\right)$. There was, however, no difference between the shelf promotion and the control conditions $\left(M_{\text {shelf }}=4.05\right.$ vs. $M_{\text {control }}=4.18$; $p=.31$ ). These results support hypothesis $2 \mathrm{~b}$.

To examine mediation, we employed a serial multiple mediator model (process model 6; Hayes 2017) to determine how promotion condition influenced the salience of quality, the participant's evaluation of the promoted product, purchase intentions. The results of the serial model with the salience of quality and the participant's evaluations of the promoted product found a significant overall indirect effect through both (5,000 draws; 95\% confidence interval [CI]: $-.1636,-.0137)$.

\section{Discussion}

Consistent with our theoretical framework, study 1 demonstrates that isolated promotions increase the salience of quality of the promoted product, leading to more favorable 
evaluations and a higher likelihood of redemption. Although the results are consistent with our predictions, this picture is incomplete as we only measured the salience of quality related to the promoted product and not that of the price.

As such, we use study 2 to examine how the salience of price and the corresponding guilt toward selecting the promoted product influence redemption. If shelf promotions increase the salience of price, participants are proposed to still feel the guilt associated with purchasing a premium brand, even at a discount. Consequently, we examine whether separating promotions from the point-of-purchase assuages guilt.

\section{STUDY 2}

Study 2 was a between-subjects experiment conducted online with $193\left(M_{\text {age }}=36.89 ; 64.1 \%\right.$ female $)$ paid workers from Amazon's MTurk.

\section{Procedure and Design}

We used a similar procedure as in study 1 , but study 2 examined how isolated promotions impact the salience of price in the redemption decision. To do this, we asked participants how guilty they felt at the thought of purchasing the promoted brand and the salience of price versus quality when deciding whether to purchase the promoted product. To further test the robustness of the effect, the promoted category was changed to ground coffee, and the promoted brand was changed to Starbucks ground coffee. As in the previous studies, participants were randomly assigned to receive an isolated promotion between the fourth and fifth purchase decisions or a shelf promotion at the time of the coffee decision. Immediately after making their coffee selection, participants answered questions about their decision for ground coffee.

\section{Measures}

We collected participants' ground coffee selections to determine the effectiveness of each type of promotion. Participants also responded to a question assessing the level of guilt they experienced when considering purchasing the promoted brand, as well as the salience of price versus quality in their coffee selection. The guilt measure asked participants to indicate "the extent that purchasing the promoted product would make you feel guilty" on a 9-point scale ( $1=$ not at all; $9=$ extremely). Then, participants indicated the importance of price and quality in the evaluation process of the promoted product on a 100-point slider ( 1 = completely focused on quality; 100 = completely focused on price) to operationalize the salience of price versus quality (Wathieu, Muthukrishnan, and Bronnenberg 2004).

\section{Results}

Supporting hypothesis 1 , a chi-square test of proportions demonstrated that the isolated (shelf) promotion increased (decreased) the likelihood of selecting the promoted product (33.3\% vs. $20.0 \%$; $\left.\chi^{2}=4.41, p=.036\right)$. An ANOVA with promotion type as a predictor variable demonstrated that the salience of price (quality) for participants in the isolated promotion condition was significantly lower (higher) than for those in the shelf promotion condition $\left(M_{\text {isolated }}=\right.$ 41.59 vs. $\left.M_{\text {shelf }}=50.00 ; F(1,191)=5.37, p=.022\right)$. Five participants failed to respond to this measure accounting for the differences in the degrees of freedom. The results corroborate the results from study 1 and support hypothesis 2 a. Isolated promotions decrease the salience of price relative to shelf promotions.

Next, we tested hypothesis $2 \mathrm{c}$ by examining how promotion type influences guilt. An ANOVA with promotion type predicting participants' guilt revealed that participants in the isolated promotion condition reported significantly less guilt about purchasing the promoted brand $\left(M_{\text {isolated }}=3.98\right.$ vs. $\left.M_{\text {shelf }}=4.68 ; F(1,191)=3.61, p=.05\right)$. Furthermore, a serial multiple mediator analysis (process model 6; Hayes 2017) confirmed that isolated promotions reduced price salience, which assuaged the level of guilt shoppers felt about purchasing the promoted brand and ultimately increased redemption decisions. In support of our theoretical framework, the results reveal a significant serial indirect effect through both price salience and guilt (5,000 draws; 95\% CI: $-.2005,-.0016)$.

\section{Discussion}

Study 2 supports our theoretical proposition that promotion type influences how shoppers decide whether to purchase promoted brands. The results suggest that consumers' focus on price relative to quality with shelf promotions evokes greater guilt at the thought of purchasing the promoted brand. In contrast, although any promotion could reduce guilt about purchasing premium brands, isolated promotions appear to evoke less guilt and encourage redemption.

In our final study, we further examine the proposed process and investigate how promotion type influences both the perceived quality of the promoted product (study 1 ), the potential guilt associated with the purchase of the promoted product (study 2), and whether each factor operates independently or in tandem with each other. We strengthen the ecological validity of our research by examining the effect in a physical grocery store setting, where participants selected a brand off the shelf after encountering shelf or isolated promotions. 


\section{STUDY 3}

In order to provide additional support for our proposed theoretical framework in a more realistic and externally valid context, study 3 was conducted in an experimental grocery store containing more than 300 products. The study was a two-level (isolated vs. shelf promotion) between-subjects design to not only test our core hypothesis that isolated promotions increase redemption likelihood, but also included process measures that allowed us to examine whether this effect is driven by the way the promotion type influences both product evaluations and participants' guilt (hypotheses $2 \mathrm{~b}$ and $2 c$ ). We argue that isolated promotions increase the salience of quality and, as a result, produce more favorable evaluations and increase the redemption likelihood (see study 1 ). At the same time, we suggest that isolated promotions also increase the redemption likelihood by reducing the salience of price, thereby reducing the level of guilt associated with purchasing premium brands (see study 2). In study 3 , we test whether the improvement of participants' evaluations and the decrease in guilt simultaneously increase redemption.

\section{Procedure and Design}

In exchange for partial course credit, 162 student participants $\left(M_{\text {age }}=20.4 ; 52.4 \%\right.$ female $)$ shopped in an experimental grocery store housed in the behavioral research laboratory at the University of Kentucky that was created with the assistance of a large national retail chain to mimic a realworld environment. The experimental store featured more than 300 products placed on three separate aisles and two end caps.

As a cover for the experiment, participants were told that they were going to test a digital shopping assistant in our experimental grocery store. This digital shopping assistant was presented through an iPad that was mounted to a shopping cart. Participants were told the shopping assistant would (1) present them with a shopping list (i.e., product categories) of items to purchase, (2) provide them with a store map that tells them where to locate the next item on the shopping list, and (3) show them promotional offers based on their progress. A picture of the store and shopping cart can be found in the appendix.

Before beginning the experiment, participants read a short description about using the digital shopping assistant and were asked to make purchases, in order, from six product categories: soda, snack bars, paper towels, cookies, coffee, and apple juice. The fifth purchase for coffee contained five options, including the promoted brand Starbucks. To manipulate the timing of the promotion, participants in the isolated promo- tion condition saw a promotion on the iPad screen following their second purchase that informed them of a $\$ .50$ price promotion for Starbucks. Those in the shelf promotional condition viewed the promotion on the shelf where the product was located. The promotion condition (isolated vs. shelf) alternated by lab sessions daily and were counterbalanced throughout the week-long experiment to eliminate time-ofday effects. After completing their shopping trip, participants returned the cart to a research assistant, went to a neighboring room, answered computer-based questions about their shopping trip, and provided demographic information.

\section{Measures}

All purchases were recorded ( $0=$ not purchased, $1=$ purchased), allowing us to examine whether promotion type influenced purchases. Next, to measure whether promotion type influenced evaluations of the promoted product, participants rated the overall value of the promoted brand on a 7point scale ( 1 = extremely low; 7 = extremely high). To measure guilt, we asked participants to indicate how guilty they felt about purchasing the promoted Starbucks ( 1 = not at all guilty; 7 = very guilty).

\section{Results}

Purchase Intentions. Our theoretical framework predicts that the timing of the promotion influences how shoppers evaluate the promoted brand, which ultimately enhances the redemption likelihood and the purchase of the promoted brand. The results of a logistic regression confirm this prediction and demonstrate that participants who encountered the isolated promotion were more likely to purchase the promoted brand (43.2\% vs. $28.4 \%$; $\beta=-0.65$; Wald $=3.84$; $p<.05)$. Thus, hypothesis 1 is supported.

Promoted Product Evaluation. To examine whether promotion type influenced the evaluation process, we conducted an ANOVA with promotion type as the independent variable and evaluations of the promoted brand, Starbuck's ground coffee, as the dependent variable. Consistent with our predictions, shoppers who encountered an isolated (shelf) promotion perceived the brand more (less) favorably ( $M_{\text {isolated }}=$ 4.64 vs. $\left.M_{\text {shelf }}=4.13 ; F(1,160)=3.90, p=.05\right)$.

We conducted a mediational analysis to determine whether the evaluations also drive the relationship between promotion type and redemption likelihood. According to our conceptual framework, participants encountering the isolated promotion would evaluate the brand more favorably and choose to purchase it. Our supposition was confirmed through 
process model 4 bootstrapping (Hayes 2017) with 5,000 resamples showing a significant indirect effect as the confidence interval does not include zero (95\% CI: - .5596, - .0016). Additionally, we ran a mediational model that controlled for the participant's experience of guilt and found that this relationship was still significant (process model' 4 with both Evaluations and Guilt; 95\% CI: -.5369, -.0056). The results are consistent with study 1 and support hypothesis $2 \mathrm{~b}$.

Guilt. To test hypothesis 2c, we conducted an ANOVA with promotion type as the independent variable and guilt experienced when participants considered purchasing Starbucks as the dependent variable. As predicted, isolated promotions led shoppers to experience less guilt ( $M_{\text {isolated }}=3.97$ vs. $\left.M_{\text {shelf }}=4.97 ; F(1,160)=6.31, p=.01\right)$, suggesting that isolated promotions may alleviate some of the guilt that often accompanies the purchase of premium brands.

To determine whether guilt drives purchase decisions, we conducted a mediation analysis. A bootstrapping procedure (process model 4; Hayes 2017) with 5,000 resamples indicates that the relationship between promotion type and redemption is mediated by guilt as the confidence interval of the indirect effect does not include zero (95\% CI: -.5405 , -.0634). Furthermore, we find that this relationship is still significant if we also include the participant's brand evaluations in the analysis (process model 4 with both guilt and evaluations; 95\% CI: $-.5035,-.0346)$. These results support hypothesis $2 \mathrm{c}$ and suggest that the effect of promotional timing on redemption is positively influenced by a more favorable evaluation of the promoted brand and a reduced sense of guilt associated with the purchase of the promoted brand.

\section{Discussion}

Study 3, conducted in an experimental grocery store, supports our core theoretical proposition that shoppers who encounter promotions separately from the point of purchase are more likely to purchase the promoted brand. The results further indicate that promotion type influences both the perceived quality of the promoted product and the guilt experienced when shoppers want to redeem it, which ultimately influences the likelihood of redemption.

\section{GENERAL DISCUSSION}

In three studies, we provide evidence that the traditional way of delivering promotions at the time shoppers view products on the shelf may be less effective for premium brands than delivering promotions in isolation. By building on principles from isolated versus shelf evaluations (Hsee and Leclerc
1998) and reason-based choice (Shafir et al. 1993), we demonstrate that isolated promotions influence how shoppers evaluate the promotion and decide whether to purchase the promoted brand. When promotions are detached from competing alternatives, shoppers focus more on the benefits rather than the costs of the promoted brand, more easily justifying purchasing premium brands.

Study 1 provides initial evidence that isolated promotions are more successful than shelf promotions for premium brands and demonstrates that isolated promotions cause participants to focus on the benefits rather than the costs of the promoted product. Study 2 provides further support by suggesting that isolated promotions shift the focus away from price, leading shoppers to experience less guilt about purchasing a premium brand. Finally, study 3 relaxes the experimental controls of a laboratory experiment and find the same effect in a physical store, while also demonstrating that isolated promotions relatively shift shoppers' focus from price to quality and influences both guilt and evaluations of the promoted brand.

\section{Limitations and Future Research}

Although our three studies provide consistent evidence that supports our theoretical framework, no work is without its limitations. One such limitation may be that some of our measures consisted of only one item. Although the reliability of a single measure can be limited, the consistent results across studies should alleviate this possibility. Additional limitations stem from the products and context in which this research was conducted. For instance, all of the products that were used in our studies were grocery products at relatively low prices. Although grocery shopping provided us with an ideal context to test isolated in-store promotions, research is needed to examine the impact of isolated promotions on a greater variety of products. For instance, further research should examine how price level, brand familiarity, and purchase frequency may influence the effectiveness of isolated promotions.

Future research could also examine how isolated promotions work with completely unplanned purchases, as participants were guided through a defined shopping trip in our studies. Although this approach aligns with past research that suggested many grocery purchases are either explicitly planned to a brand level (i.e., Coca Cola) or somewhat planned at a category level (i.e., cola; Stilley, Inman, and Wakefield 2010), it is possible that isolated promotions may have different effects for completely unplanned purchases. Given that research has suggested category-level promotions (i.e., "save 
$\$ 2$ on cereal") increase consumer shopping time and monetary spending (Hui et al. 2013), these isolated brand-specific promotions may also help retailers drive shoppers to different parts of the store.

Additionally, the influence of other moderators on isolated promotions should also be examined. Although our findings suggest that isolated promotions should benefit premium brands in general, more research is needed to determine whether other product characteristics, such as whether the product is hedonic or utilitarian, interact with a promotion's timing and influence the relative salience of price and quality in a shopper's redemption decision. This could further reconcile the conflicting research as to what type of promotions would be most effective for hedonic products (Chandon et al. 2000; Kivetz and Zheng 2017).

Finally, research is needed to understand the nuances and boundaries of isolated promotions. For instance, the precise timing of the promotional encounter within a shopping trip may alter their influence. If the promotion is too early, shoppers could forget about it by the time they reach the ultimate purchase decision. If the promotion is too late, it may be integrated into the price of the product (Yan and Sengupta 2011). Furthermore, as shoppers tend to encounter changing information throughout the shopping experience (Lee and Ariely 2006), promotions may be more or less powerful depending upon whether they occur early or late. Last, as they may also influence the effectiveness of isolated promotions, it would also be fruitful to investigate how instore variables, such as within-trip spending or sensitivity to prices (Stilley et al. 2010; Sheehan and Van Ittersum 2018), may alter the influence of promotions.

\section{Managerial Implications}

Our findings also have powerful implications for retailers. As promotions are one of the most commonly used marketing tools, retailers benefit by understanding how different types of promotions influence promotional response. Not only do our results illustrate how retailers and manufacturers could avoid the deleterious consequences of drawing shoppers' attention to prices with promotions, but they also suggest that a discount's magnitude may be less critical for isolated promotions as they lead shoppers to focus more on the benefits, relative to the costs, of the purchase. Thus, retailers could save a portion of their promotional budget by using isolated promotions. Additionally, isolated promotions stimulate thoughts about the promoted products' benefits (e.g., relatively its costs) that not only influence sales but also increase consumers' evaluations of the promoted product. Conse- quently, manufacturers may want to assist retailers with isolated promotion campaigns. It is also possible that an isolated promotion's influence could spill over to a consumer's response to other promotions or spending decisions (Heilman, Nakamoto, and Rao 2002; Janakiraman, Meyer, and Morales 2006; Sheehan et al. 2019).

In conclusion, our findings show that brands, according to their positioning, may benefit from shifting the moment that consumers encounter a promotion. This research demonstrates that promotions can be more effective and persuasive if they are offered before shoppers encounter the promoted product on the shelf. Specifically, when customers encounter isolated promotions, they appear to be more likely to think about the benefits rather than costs of the promoted product, which leads them to evaluate the product more favorably and purchase the promoted product.

\section{REFERENCES}

Ailawadi, Kusum, and Scott Neslin (1998), "The Effect of Promotion on Consumption: Buying More and Consuming It Faster," Journal of Marketing Research, 35 (3), 390-98.

Ailawadi, Kusum, Scott Neslin, and Karen Gedenk (2001), "Pursuing the Value-Conscious Consumer: Store Brands versus National Brand Promotions," Journal of Marketing, 65 (1), 71-89.

Aydinli, Aylin, Marco Bertini, and Anja Lambrecht (2014), "Price Promotion for Emotional Impact," Journal of Marketing, 78 (4), 80-96.

Bazerman, Max, Don A. Moore, A. E. Tenbrunsel, K. A. Wade-Benzoni, and S. Blount (1999), "Explaining How Preferences Change across Joint versus Separate Valuation," Journal of Economic Behavior and Organization, 39 (1), 41-58.

Biswas, Abhijit, Sandeep Bhowmick, Abhijit Guha, and Dhruv Grewal (2013), "Consumer Evaluations of Sale Prices: Role of the Subtraction Principle,” Journal of Marketing, 77 (4), 49-66.

Briesch, Richard (1997), "Does It Matter How Price Promotions Are Operationalized?" Marketing Letters, 8 (2), 167-81.

Chandon, Pierre, Brian Wansink, and Gilles Laurent (2000), "A Benefit Congruency Framework of Sales Promotion Effectiveness," Journal of Marketing, 64 (4), 65-81.

Frederick, Shane, Nathan Novemsky, Jing Wang, Ravi Dhar, and Stephen Nowlis (2009), "Opportunity Cost Neglect," Journal of Consumer Research, 36 (4), 553-61.

Hayes, Andrew F. (2017), Introduction to Mediation, Moderation, and Conditional Process Analysis: A Regression-Based Approach, New York: Guilford.

Heilman, Carrie M., Kent Nakamoto, and Ambar G. Rao (2002), "Pleasant Surprises: Consumer Response to Unexpected In-store Coupons," Journal of Marketing Research, 39 (2), 242-52.

Hsee, Christopher K., and France Leclerc (1998), "Will Products Look More Attractive When Evaluated Jointly or When Evaluated Separately?" Journal of Consumer Research, 25 (2), 175-86.

Hui, Sam, J. Jeffrey Inman, Yanliu Huang, and Jacob Suher (2013), “The Effect of In-Store Travel Distance on Unplanned Spending: Applications to Mobile Promotion Strategies," Journal of Marketing, 77 (March), 1-16.

Janakiraman, Narayan, Robert Meyer, and Andrea C. Morales (2006), "Spillover Effects: How Consumers Respond to Unexpected Changes in Price and Quality," Journal of Consumer Research, 33 (3), 361-69. 
Kahneman, Daniel, and Shane Frederick (2002), "Representativeness Revisited: Attribute Substitution in Intuitive Judgment," in Heuristics and Biases: The Psychology of Intuitive Judgment, ed. Thomas Gilovich, Dale Griffin, and Daniel Kahneman, Cambridge: Cambridge University Press, 49-81.

Kivetz, Ran, and Itamar Simonson (2002), "Earning the Right to Indulge: Effort as a Determinant of Customer Preferences toward Frequency Program Rewards," Journal of Marketing Research, 39 (2), 155-70.

Kivetz, Ran, and Yuhuang Zheng (2017), "The Effects of Promotions on Hedonic versus Utilitarian Purchases," Journal of Consumer Psychology, 27 (1), 59-68.

Lee, Leonard, and Dan Ariely (2006), "Shopping Goals, Goal Concreteness, and Conditional Promotions," Journal of Consumer Research, 33 (1), 60 70.

Leone, Richard, and Srini Srinivasan (1996), "Coupon Face Value: Its Impact on Coupon Redemptions, Brand Sales, and Brand Profitability," Journal of Retailing, 72 (3), 273-89.

Loewenstein, George, and Drazen Prelec (1993), "Preferences for Sequences of Outcomes," Psychological Review, 100 (1), 91-108.

Mela, Carl, Sunil Gupta, and Donald Lehmann (1997), "The Long-term Impact of Promotion and Advertising on Consumer Brand Choice," Journal of Marketing Research, 34 (2), 248-61.

Nunes, Joseph C., and C. Whan Park (2003), "Incommensurate Resources: Not Just More of the Same," Journal of Marketing Research, 40 (1), 26 38.

Okada, Erica Mina (2005), "Justification on Consumer Choice of Hedonic and Utilitarian Goods," Journal of Marketing Research, 42 (1), 43-53.

Papatla, Purushottam, and Lakshman Krishnamurthi (1996), "Measuring the Dynamic Effects of Promotions on Brand Choice," Journal of Marketing Research, 33 (1), 20-35.

Prelec, Drazen, and George Loewenstein (1998), "The Red and the Black: Mental Accounting of Savings and Debt," Marketing Science, 17 (1), 4-28.
Raghubir, Priya, and Kim Corfman (1999), "When Do Price Promotions Affect Pretrial Brand Evaluations?” Journal of Marketing Research, 36 (2), 211-22.

Rao, Akshay R., and Kent B. Monroe (1989), “The Effect of Price, Brand Name, and Store Name on Buyers' Perceptions of Product Quality: An Integrative Review," Journal of Marketing Research, 26 (3), 351-57.

Shafir, Edgar, Itamar Simonson, and Amos Tversky (1993), "Reason-Based Choice," Cognition, 49 (1-2), 11-36.

Sheehan, Daniel, David M. Hardesty, Alexander H. Ziegler, and Haipeng Allan Chen (2019), "Consumer Reactions to Price Discounts across Online Shopping Experiences," Journal of Retailing and Consumer Services, 51, 129-38.

Sheehan, Daniel, and Koert Van Ittersum (2018), "In-Store Spending Dynamics: How Budgets Invert Relative-Spending Patterns," Journal of Consumer Research, 45 (1), 49-67.

Slovic, Paul (1972), "Information Processing, Situation Specificity, and the Generality of Risk-taking Behavior," Journal of Personality and Social Psychology, 22 (1), 128-34.

Stilley, Karen, J. Jeffery Inman, and Kirk Wakefield (2010), "Spending on the Fly: Mental Budgets, Promotions, and Spending Behavior,” Journal of Marketing, 74 (May), 34-47.

Van Ittersum, Koert, Joost M. E. Pennings, Brian Wansink, and Hans C. M. van Trijp (2007), "The Validity of Attribute-Importance Measurement: A Review," Journal of Business Research, 60 (11), 1177-90.

Van Ittersum, Koert, Brian Wansink, Joost M. E. Pennings, and Daniel Sheehan (2013), "Smart Shopping Carts: How Real-Time Feedback Influences Spending," Journal of Marketing, 77 (6), 21-36.

Wathieu, Luc, A. V. Muthukrishnan, and Bart J. Bronnenberg (2004), “The Asymmetric Effect of Discount Retraction on Subsequent Choice," Journal of Consumer Research, 31 (3), 652-57.

Yan, Dengfeng, and Jaideep Sengupta (2011), "Effects of Construal Level on the Price-Quality Relationship," Journal of Consumer Research, 38 (2), 376-89. 